\title{
Microbiological profile, comorbidity, incidence and rate analysis of catheter associated urinary tract infections in adult intensive care unit
}

\author{
Arunagiri Ramesh ${ }^{1}$, Anand B Janagond ${ }^{2, *}$, Sundaramurthy Raja ${ }^{3}$, Sorakka Pandurangan Gobinathan ${ }^{4}$, \\ Jhansi Charles ${ }^{5}$
}

\author{
${ }^{\mathbf{1 , 2}}$ Associate Professor, ${ }^{\mathbf{3}}$ Assistant Professor, ${ }^{4}$ MBBS Student, ${ }^{5}$ Professor \& HOD, Dept. of Microbiology, ${ }^{\mathbf{1 , 3}, 4,5}$ Velammal Medical \\ College Hospital and Research Institute, Madurai, Tamilnadu, ${ }^{2}$ S. Nijalingappa Medical College, Bagalkot, Karnataka, India

\section{*Corresponding Author:} \\ Email: anandbj@gmail.com
}

\begin{abstract}
Introduction: Catheter-associated urinary tract infections (CAUTI) being the commonest hospital-acquired infection (HAI) [40\%], its burden, aetiology along with antibiotic susceptibility is essential to implement and monitor an effective infection control program.

Aims: To assess the incidence and rate of CAUTI in a tertiary care hospital and to identify the common organisms and their antibiotic sensitivity pattern.

Settings and Design: Prospective hospital based observational study was carried out in a tertiary care hospital in South Tamilnadu for a period of 2 months (June 2016 to July 2016) after obtaining the Institutional Ethics committee approval.

Materials and Methods: Total of 100 catheterized adult ICU patients were observed for signs of UTI on a daily basis. On clinical suspicion of UTI, urine sample was analysed microbiologically. CAUTI among various gender and age groups; pathogenic isolates, antibiotic sensitivity pattern and associated co-morbid conditions were expressed as percentages

Results: Incidence of CAUTI was $16 / 100$ catheterization. Device utilization ratio was 0.72 . CAUTI rate was $36.2 / 1000$ catheter days. CAUTI was commonly seen among patients with $>80$ years, females with altered sensorium. Diabetes mellitus (35.7\%) was the most common comorbid condition followed by TB (25\%). Risk of CAUTI after 3-5 days of catheterization was $11.7 \%$ and proportionately increased with prolonged catheterization (100\% if $>20$ days). Escherichia coli (37.5\%) followed by Candida Spp. (25\%) were common pathogens among 3-5days of catheterization. Pseudomonas Spp. was the commonest isolate after one week of catheterization. Imipenem, colistin resistance was highest among pseudomonas.

Conclusions: CAUTI rate was higher than the benchmark set by NHSN (0-4). Appropriate health education, strict infection control practices, appropriate antibiotic policy, proper guided bundle care of catheter are need of the hour to prevent the CAUTI.

Keywords: Adult ICU, CAUTI, Comorbidity analysis, Incidence, Microbiological Profile.

Key Messages: Incidence of CAUTI was 16 per 100 catheterization and the CAUTI rate was 36.2 per 1000 catheter days which was higher to the benchmark of NHSN (0-4). Risk of CAUTI proportionately increased with prolonged catheterization from $11.7 \%$ after $3-5$ days to $100 \%$ after 20 days. Escherichia coli $(37.5 \%)$ followed by Candida $(25 \%)$ were common pathogens among 3-5days of catheterization. Pseudomonas was the common isolate after one week of catheterization.
\end{abstract}

\section{Introduction}

Hospital-acquired infections (HAI) are the leading cause of morbidity and mortality in healthcare settings globally, especially in intensive care units (ICUs). ${ }^{1,2}$ HAIs also increase the economic burden on the patients in the form of prolonged hospital stay, lost work-days, laboratory and drug costs. ${ }^{3}$

Urinary tract infections (UTI) is the second commonest infection in the community, whereas it is the most common HAI, accounting for $40 \%$ of all HAIs. ${ }^{4}$ Though, many predisposing factors like gender, age, malnutrition, low socioeconomic conditions with poor hygiene, structural and functional abnormalities of urinary tract are reported as risk factors for developing UTI; the indwelling catheter which is an essential part of modern medical care; inserted to monitor various clinical parameters, itself is the major risk factor for hospital-acquired UTI. $^{6}$ Approximately $25 \%$ of hospitalized patients and $70 \%$ critically ill ICU patients undergo urinary catheterization. ${ }^{7}$

CAUTI (CDC National Healthcare Safety Network (NHSN)) is defined as UTI where an indwelling urinary catheter was in place for more than two calendar days on the date of event, with day of device placement being Day one, and an indwelling urinary catheter was in place on the date of event or the day before. If an indwelling urinary catheter was in place for more than two calendar days and then removed, the date of the event for the CAUTI must be the day of discontinuation or the next day with culture positivity. ${ }^{8}$ Each day when the indwelling urinary catheter remains, a patient has $3 \%-10 \%$ increased the risk of acquiring CAUTI and incidence of bacteriuria with catheter reaches nearly $100 \%$ in four weeks duration. ${ }^{9}$

Microbiological profile and antimicrobial sensitivity pattern of CAUTI vary considerably between regions and time to time. ${ }^{10}$ Nearly $30-40 \%$ of the gramnegative septicemia acquired in the hospital originates in the urinary tract. Inappropriate and recurrent use of antibiotics to treat CAUTI can lead to antimicrobial resistance. ${ }^{11}$ Multiple risk factors like quality of aseptic technique, duration of catheterization, hand hygiene and care of catheter can affect the occurrence of CAUTI. Also, HAI directly reflects on the quality care of the 
healthcare setting; so knowledge about the rates of HAI and organism associated with their antibiotic susceptibility is essential to implement the infection control system in a proper manner. ${ }^{12,13}$ The present study was aimed to assess the incidence and rate of CAUTI in a tertiary care hospital and to identify the common causative organisms and their antibiotic sensitivity pattern.

\section{Materials and Methods}

The prospective hospital-based observational study was carried out in a tertiary care multispeciality hospital in South, Tamilnadu for a period of 2 months (June 2016 to July 2016) after obtaining the Institutional Ethics committee approval.

A total of 100 adult patients including both genders with indwelling urinary Foley's catheter admitted in ICUs during the study period were included in the study. Catheterized ICU patients transferred to general ward were also followed up by two calendar days following the transfer ( $1^{\text {st }}$ day being the day of transfer). Patients only on condom catheter or on nephrostomy tube/ suprapubic catheters were excluded from the study.

Urinary catheter insertion, maintenance, and removal were done based on standard guidelines. During the study period, catheterized study participants were observed for local and systemic signs of UTI, meticulously on daily basis. On clinical suspicion of UTI, a urine sample was collected by disinfecting a portion of the catheter tubing with alcohol \& aspirating the urine aseptically by puncturing the tubing with a sterile syringe and sent to the microbiology laboratory for Culture and Sensitivity test immediately.

Sample Processing: The urine was cultured in Nutrient agar and MacConkey agar by a Semi uantitative method -calibrated $1 \mu \mathrm{L}$ loop with a diameter of $1.3 \mathrm{~mm}$ (Himedia Cat.no:LA023) without intermittent flaming and incubated at $35-37^{\circ} \mathrm{C}$ for $24 \mathrm{~h}$. The diagnosis of UTI was made by means of a significant positive urine culture count of $>10^{5}$ colony forming units (CFU) per $\mathrm{ml}$. The pathogenic organism was further characterized to species level using appropriate biochemicals tests.

Antibiotic sensitivity test was done using Kirby Bauer disc diffusion method as per CLSI guidelines.
Antibiotic discs were bought from Hi-Media laboratories, Mumbai.

\section{Statistical Analysis}

Incidence rate, Device utilization rate and CAUTI rate were calculated using the formula

1. Incidence Rate $=($ No. of CAUTI $) \times 100 /($ No. of catheterized patients)

2. Device Utilization Rate $=$ No. of indwelling catheter days/No. of patient days

3. CAUTI Rate $=($ No. of CAUTI $) \times 1000 /($ No. of indwelling catheter days)

CAUTI among various gender and age; pathogenic isolates, antibiotic sensitivity pattern and associated comorbid conditions were expressed as percentage.

\section{Results}

Among the total 100 catheterized adult ICU patients, $66 \%$ were males and $34 \%$ were females. Catheterization was highest among 41-60 age group $(51 \%)$. The incidence of CAUTI was $16 \%$ (16/100). A total number of patient days was 607; Number of indwelling catheter days was 441; Device utilization ratio was 0.72 . CAUTI rate was 36.2 per 1000 catheter days.

The incidence of CAUTI was highest among the elderly (>80 years) individuals $(50 \%)$ (Table 1$)$. The difference in CAUTI incidence among females $(17.6 \%$, $6 / 34)$ and males $(15.1 \%, 10 / 66)$ was statistically not significant. The incidence of CAUTI was higher in head injury patients with altered sensorium who were admitted in neuro ICU $(42.8 \%)$ compared to the patients with other system involvements (Table 2). The commonest comorbid condition associated with CAUTI was diabetes mellitus $(35.7 \%)$ followed by tuberculosis (25\%) (Fig. 1). All the patients catheterized for more than 20 days had developed CAUTI (Table 3).

Common uropathogenic isolated was Escherichia coli $(37.5 \%)$ followed by Candida spp (25\%) (Fig. 2). All the Escherichia coli isolates were sensitive to Amikacin, Netilmicin, Colistin and Tigecycline. Most (66.7\%) of the Pseudomonas aeruginosa isolates were sensitive to Colistin. Thus most of the Gram negative bacilli isolated from CAUTI were sensitive to Colistin, Amikacin and Tigecycline (Table 4).

Table 1: Incidence of CAUTI with age

\begin{tabular}{|c|c|c|c|}
\hline $\begin{array}{c}\text { Age group } \\
\text { (Years) }\end{array}$ & $\begin{array}{c}\text { No. of patients } \\
\text { enrolled }\end{array}$ & $\begin{array}{c}\text { No. of CAUTI } \\
\text { cases }\end{array}$ & Percentage \\
\hline $15-20$ & 2 & 0 & $0 \%$ \\
\hline $21-40$ & 18 & 4 & $22.2 \%$ \\
\hline $41-60$ & 51 & 8 & $15.6 \%$ \\
\hline $61-80$ & 25 & 2 & $8 \%$ \\
\hline$>80$ & 4 & 2 & $50 \%$ \\
\hline
\end{tabular}


Table 2: Incidence of CAUTI with respect to system involved in the primary disease/condition of patients

\begin{tabular}{|l|c|c|c|}
\hline $\begin{array}{c}\text { System involved in the } \\
\text { primary disease }\end{array}$ & $\begin{array}{c}\text { No. of patients } \\
\text { enrolled }\end{array}$ & $\begin{array}{c}\text { No. of CAUTI } \\
\text { cases }\end{array}$ & Percentage \\
\hline CNS & 21 & 9 & $42.8 \%$ \\
\hline RS & 7 & 1 & $14.3 \%$ \\
\hline CVS & 6 & 0 & $0 \%$ \\
\hline GIT & 9 & 0 & $0 \%$ \\
\hline Renal & 19 & 4 & $21.1 \%$ \\
\hline Metabolic & 7 & 0 & $0 \%$ \\
\hline Musculoskeletal & 4 & 0 & $0 \%$ \\
\hline Post Operative & 25 & 2 & $0 \%$ \\
\hline Poison & 2 & 0 & $0 \%$ \\
\hline $\begin{array}{l}\text { CNS- Cardiovascular system, RS - Respiratory system, CVS - Cardiovascular system, GIT - } \\
\text { Gastrointestinal system }\end{array}$
\end{tabular}

Table 3: Interval between catheterization and Appearance of features of UTI

\begin{tabular}{|l|c|c|c|}
\hline Catheter days & No. of patients enrolled & No. of CAUTI cases & Percentage \\
\hline $1-2$ & 35 & 0 & $0 \%$ \\
\hline $3-5$ & 51 & 6 & $11.7 \%$ \\
\hline $6-10$ & 5 & 3 & $60 \%$ \\
\hline $10-15$ & 3 & 2 & $66.6 \%$ \\
\hline $15-20$ & 3 & 2 & $66.6 \%$ \\
\hline$>20$ & 3 & 3 & $100 \%$ \\
\hline
\end{tabular}

Table 4: Antibiotic Sensitivity Pattern (\%)

\begin{tabular}{|c|c|c|c|c|}
\hline $\begin{array}{l}\text { Uropathogen } \\
\text { (No.) }\end{array}$ & $\begin{array}{c}\text { Escherichia } \\
\text { coli }(6)\end{array}$ & $\begin{array}{l}\text { Klebsiella } \\
\text { pneumoniae } \\
(3)\end{array}$ & $\begin{array}{c}\text { Enterobacter } \\
\text { spp (1) }\end{array}$ & $\begin{array}{l}\text { Pseudomonas } \\
\text { aeruginosa } \\
(2)\end{array}$ \\
\hline CTR & 16.6 & 0 & 0 & - \\
\hline CPM & 33.2 & 0 & 0 & 0 \\
\hline PIT & 66.4 & 33.3 & 0 & 0 \\
\hline $\mathrm{AK}$ & 100 & 33.3 & 100 & 50 \\
\hline GEN & 66.4 & 33.3 & 0 & 50 \\
\hline CIP & 16.6 & 0 & 0 & 0 \\
\hline NET & 100 & 33.3 & 100 & 0 \\
\hline IMP & 82.6 & 33.3 & 100 & 0 \\
\hline $\mathrm{CO}$ & 66.4 & 0 & 0 & - \\
\hline $\mathrm{CL}$ & 100 & 100 & 100 & 50 \\
\hline LE & 16.6 & 0 & 0 & - \\
\hline TGC & 100 & 100 & - & - \\
\hline NIT & 82.6 & 66.6 & 0 & - \\
\hline $\mathrm{OF}$ & 16.6 & 0 & 100 & 0 \\
\hline DOX & 33.2 & 0 & 100 & - \\
\hline CAZ & 16.6 & 0 & 0 & 0 \\
\hline \multicolumn{5}{|c|}{$\begin{array}{l}\text { CTR- Ceftriaxone; CPM- Cefepime; PIT- Piperacillin-Tazobactum; AK- Amikacin; GEN- } \\
\text { Gentamicin; CIP- Ciprofloxacin; NET- Netilmicin; IMP- Imipenam; CO- Cotrimoxazole; CL- } \\
\text { Colistin; LE- Levofloxacin; TGC- Tigecycline; NIT- Nitrofurantoin; OF- Ofloxacin; DOX- } \\
\text { Doxycycline ; CAZ- Ceftazidime. }\end{array}$} \\
\hline
\end{tabular}




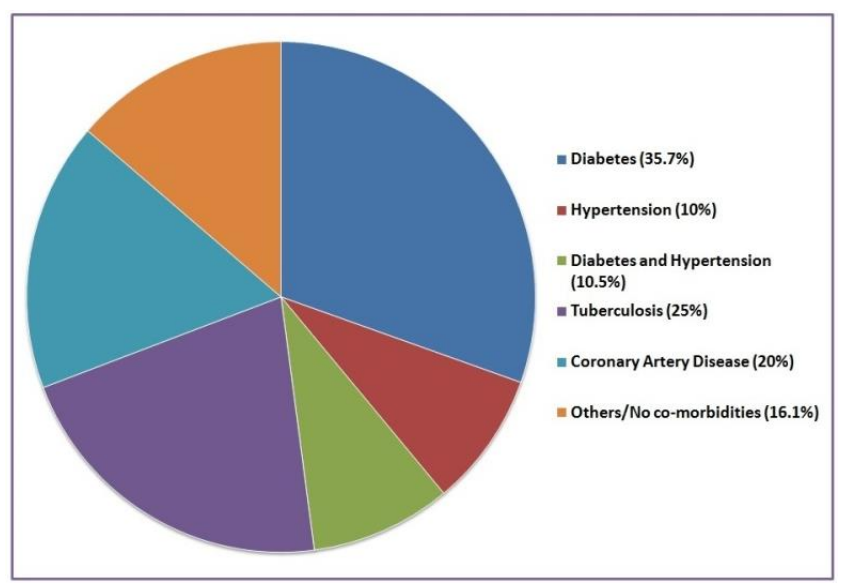

Fig. 1: Comorbid conditions associated with CAUTI

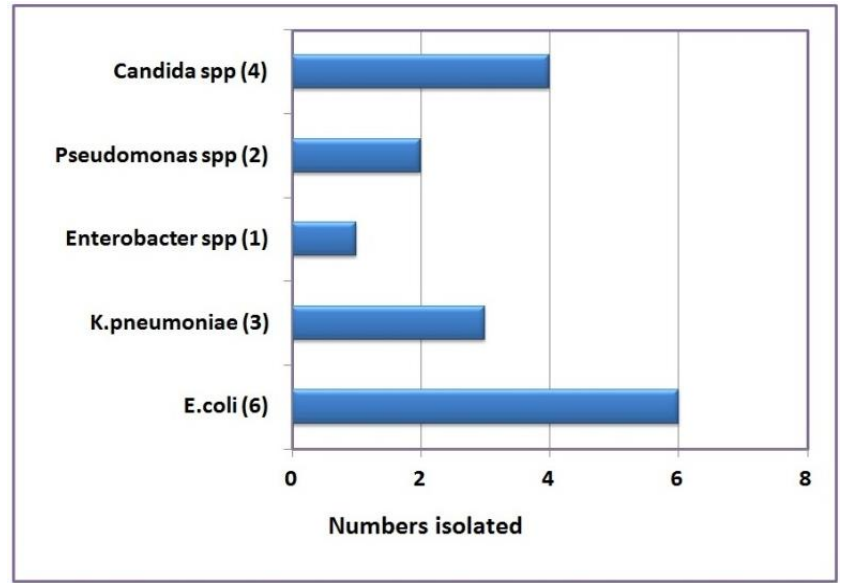

\section{Fig. 2: Uropathogens isolated from CAUTI}

\section{Discussion}

HAI directly reflect on the quality care of the healthcare settings. CAUTI which is the most common HAI was the first hospital-acquired complication chosen by the Centers for Medicare and Medicaid Services in 2008 as the basis for denial of additional payment to hospitals. ${ }^{14}$ An acceptable CAUTI rate was up to four per 1000 catheter days as given by NHSN report of U.S.A. ${ }^{15}$ If not aseptically inserted or maintained, the catheter itself may act as a portal of entry for the pathogen. Catheter-associated colonization is usually asymptomatic in healthy patients, which resolves spontaneously after removal of the catheter. In contrary, if the colonization persists that leads to infection in susceptible patients. ${ }^{16}$ Cystitis, epididymitis, prostatitis, pyelonephritis and septicemia due to Gram-negative bacteremia are some of the complications encountered in high-risk group. Furthermore, in-patient deaths among the patients of CAUTI are two to three-times higher than that among the non-bacteriuric patients. ${ }^{17}$

In this study, device utilization ratio was 0.72 which was comparable to the study report of Choudhuri JA et al $^{14}$ in ICUs (0.77). In contrary to this, M. Todd Greene $\mathrm{et}_{\mathrm{al}} \mathrm{l}^{18}$ reported the low device utilization ratio
(0.5) in non ICU setup. This comparison clearly explains that catheter utilization is always high in ICU setup and thus the risk of CAUTI in ICU could be proportionately higher.

In this study, the incidence of CAUTI was found to be 16 per 100 catheterization which was lesser than the study report of Mahim Koshariya et al, Mangukiya JD et al, Gupta $\mathrm{V}$, et al, Wazait HD et al, Chanda R et al, and Mulhall et $\mathrm{al}^{12-20}$ who reported CAUTI incidence of $27,30.71,36.3,38.75,41,44$ per 100 catheterization respectively. Even though its incidence appears lesser, it is not up to the standard of NHSN. This variability of incidence could be due to the varying place of surveillance as reported by Mangukiya JD et $\mathrm{al}^{20}$ that CAUTI in Urology ward patients $(33.33 \%)$ was higher than ICU patients $(30.71 \%)$. This indicates that even though CAUTI incidence is higher in ICU setup; certain in-patient areas such as Urology/Nephrology wards may have a higher incidence, thus contributing to a significant percentage of CAUTI among non-ICU patients. Further research could be done in this angle to assess the burden of CAUTI in non-critically ill patients. These patients are more likely to have an acute or chronic renal functional compromise. In the latter case, device utilization may be at a higher rate than ICU 
patients. This could probably explain the higher rate of CAUTI in these groups of patients.

CAUTI rate was 36.2 per 1000 catheter days which was higher than that reported by Sabir et al, Duszyńska et $a l$, Derya keten et al. ${ }^{5,25,26}$ who reported a CAUTI rate of 3.65, 7.16 and 9.6 per 1000 catheter days respectively and it is not meeting the NHSN standard too. This may be due to better infrastructure, availability of trained staff, strict infection control practices and an appropriate antibiotic policy, proper guided bundle care for both procedure and maintenance of catheter which we are planning to implement.

In the present study, CAUTI was most commonly seen among older age group ( $>80$ years) which is in concordance with Chanda $\mathrm{R}$ et $a l,{ }^{23}$ who also reported old age itself as a predisposing factor for CAUTI(Table 1). Even though no statistical significance was found between the incidence of CAUTI and gender, CAUTI was slightly common ( $2.5 \%$ higher incidence) among the female patients, which is also comparable with other studies. ${ }^{9,18}$ This increased risk in women is likely to be due to the shorter female urethra, urethra being in close proximity to the anus and hormonal influences.

Incidence of CAUTI was higher in head injury /altered sensorium patients (42.8\%) who were admitted to neuro ICU compared to those patients with diagnosis/disease condition affecting other organ systems, which was in concordance with Umesh $\mathrm{S}$ Kamat et al. ${ }^{27}$ Altered sensorium and also high severity of the underlying illness are important and common indications for urinary catheterization; both of them independently act as the risk factors for CAUTI (Table 2).

In this study, diabetes mellitus $(35.7 \%)$ was the most common comorbid condition associated with CAUTI which was also the major comorbid condition reported in other similar studies. ${ }^{18,23,24}$ In the present study, when compared to above-mentioned studies, tuberculosis $(25 \%)$ was also found to be the other important comorbid condition associated with CAUTI (Fig. 1).

In the present study, the risk of UTI after 3-5 days of catheterization was $11.7 \%$ and the risk proportionately increased with prolonged catheterization which reaches $100 \%$ if the catheter was in place for $>20$ days. This is similar to the study conducted by Dalen et $a l .{ }^{28}$ From this fact, the risk of CAUTI was almost 5 times higher after the $5^{\text {th }}$ day of catheterization (Table 3).

Commonest uropathogen in this study was Escherichia coli $(37.5 \%)$ which was similar to the results of several other studies. ${ }^{9,16,18,23}$ Escherichia coli remains the common bacterial isolate for patients who develop symptoms of UTI in a short course catheterization (3-5days), in contrary Pseudomonas was the common isolate after one week of catheterization which is in concordance with the findings of Wazait $\mathrm{HD}$, et al. ${ }^{22}$ and Candida spp (25\%) was the second most common isolate in our study. This emphasises the need to actively look for fungal causes of CAUTI in addition to bacterial causes.

Among the Enterobacteriaceae members, E.coli, Klebsiella pneumoniae, Enterobacter spp were uniformly sensitive (100\%) to Colistin whereas E.coli \& Enterobacter spp were 100\% sensitive to Amikacin. Klebsiella pneumoniae differed in this aspect by only $25 \%$ being sensitive to Amikacin. Amomg the two Pseudomonas aeuruginosa isolates, one was resistant to colistin.

Imipenem-resistance was seen in 25\% (3/12) Gram negative isolates. One Pseudomonas aeruginosa was resistant to colistin, an antibiotic that is considered as a last resort drug. This reveals that our isolates are multidrug-resistant and similar findings were observed by Kazi et al. ${ }^{29}$

This indicates measures like meticulous intervention in the form of hand hygiene, appropriate catheter maintenance practices, well defined antibiotic policy and properly guided infection control programs can reduce the extent of multidrug-resistant pathogen not only in CAUTI patients but also for the hospital in general.

\section{Conclusion}

HAI directly reflect on the quality care of the hospital and efficacy of interventions. CAUTI rate in our ICU was 36.2 per 1000 catheter days which is much high compared to the benchmark set by NHSN. So appropriate measures of educating the paramedical staff, strict infection control practices and an appropriate antibiotic policy, proper guided bundle care for both procedure and maintenance of catheter are the need of the hour to prevent the CAUTI which in turn can lessen the economic burden, work loss, and mental stress.

\section{Acknowledgement}

Authors are thankful to Dr. Jhansi Charles, HOD \& Professor, Microbiology who helped us in every aspect starting from study formulation, reporting and compiling of the results and analysis of manuscript.

Source(S) of Support: Indian Council for Medical Research (ICMR) under Short Term Studentship Program 2016 (Reference Id : 2016-03896).

\section{Presentation at a Meeting: Nil Conflicting Interest: Nil}

\section{References}

1. Ding J-G, Sun Q-F, Li K-C, Zheng M-H, Miao X-H, Ni $\mathrm{W}$, et al. Retrospective analysis of nosocomial infections in the intensive care unit of a tertiary hospital in China during 2003 and 2007. BMC Infect Dis. 2009 Jul 25;9:115.

2. Parida S, Mishra SK. Urinary tract infections in the critical care unit: A brief review. Indian J Crit Care Med 
Peer-Rev Off Publ Indian Soc Crit Care Med.

2013;17(6):370-4.

3. Leone M, Garnier F, Avidan M, Martin C. Catheterassociated urinary tract infections in intensive care units. Microbes Infect. 2004 Sep;6(11):1026-32.

4. Clec'h C, Schwebel C, Français A, Toledano D, Fosse J$\mathrm{P}$, Garrouste-Orgeas M, et al. Does catheter-associated urinary tract infection increase mortality in critically ill patients? Infect Control Hosp Epidemiol. 2007 Dec;28(12):1367-73.

5. Keten D, Aktas F, Tunccan OG, Dizbay M, Kalkanci A, Biter G, et al. Catheter-associated urinary tract infections in intensive care units at a university hospital in Turkey. Bosn J Basic Med Sci. 2014 Nov;14(4):227-33.

6. Erben N, Alpat SN, Kartal ED, Ozgüneş I, Usluer G. [Analysis of the risk factors in nosocomial urinary tract infections and effect of urinary catheter use on distribution of the causative agents]. Mikrobiyol Bul. 2009 Jan;43(1):77-82.

7. Bagshaw SM, Laupland KB. Epidemiology of intensive care unit-acquired urinary tract infections. Curr Opin Infect Dis. 2006 Feb;19(1):67-71.

8. Safety P. National Healthcare Safety Network (NHSN) Overview. [cited 2017 Jul 6];Available from: https://www.cdc.gov/nhsn/pdfs/validation/2016/pcsmanu al_2016.pdf.

9. Lo E, Nicolle LE, Coffin SE, Gould C, Maragakis LL, Meddings J, et al. Strategies to prevent catheterassociated urinary tract infections in acute care hospitals: 2014 update. Infect Control Hosp Epidemiol. 2014 May;35(5):464-79.

10. Nicolle LE. Catheter associated urinary tract infections. Antimicrob Resist Infect Control. 2014 Jul 25;3:23.

11. Guggenbichler JP, Assadian O, Boeswald M, Kramer A. Incidence and clinical implication of nosocomial infections associated with implantable biomaterials catheters, ventilator-associated pneumonia, urinary tract infections. GMS Krankenhaushygiene Interdiszip [Internet]. 2011 Dec 15 [cited 2017 Jul 6];6(1). Available from:

http://www.ncbi.nlm.nih.gov/pmc/articles/PMC3252661/

12. Gould CV, Umscheid CA, Agarwal RK, Kuntz G, Pegues DA, Healthcare Infection Control Practices Advisory Committee. Guideline for prevention of catheterassociated urinary tract infections 2009. Infect Control Hosp Epidemiol. 2010 Apr;31(4):319-26.

13. Stamm WE. Catheter-associated urinary tract infections: epidemiology, pathogenesis, and prevention. Am J Med. 1991 Sep 16;91(3B):65S-71S.

14. Choudhuri JA, Pergamit RF, Chan JD, Schreuder AB, McNamara E, Lynch JB, et al. An electronic catheterassociated urinary tract infection surveillance tool. Infect Control Hosp Epidemiol. 2011 Aug;32(8):757-62.

15. Safety P. National Healthcare Safety Network (NHSN) Overview. [cited 2017 Jul 31]; Available from: https://www.cdc.gov/nhsn/pdfs/validation/2016/pcsmanu al_2016.pdf

16. Jacobsen SM, Stickler DJ, Mobley HLT, Shirtliff ME. Complicated Catheter-Associated Urinary Tract Infections Due to Escherichia coli and Proteus mirabilis. Clin Microbiol Rev. 2008 Jan;21(1):26-59.

17. Warren JW. Catheter-associated urinary tract infections. Int J Antimicrob Agents. 2001 Apr;17(4):299-303.

18. Greene MT, Fakih MG, Fowler KE, Meddings J, Ratz D, Safdar N, et al. Regional variation in urinary catheter use and catheter-associated urinary tract infection: results from a national collaborative. Infect Control Hosp Epidemiol. 2014 Oct;35 Suppl 3:S99-106.
19. Koshariya M, Songra MC, Namdeo R, Chaudhary A, Agarwal S, Rai A. Prevalence of pathogens and their antimicrobial susceptibility in catheter associated urinary tract infection. 2015 [cited 2017 Jul 31]; Available from: http://imsear.li.mahidol.ac.th/handle/123456789/164593

20. Mangukiya J, Patel K, Vegad M. Study of incidence and risk factors of urinary tract infection in catheterised patients admitted at tertiary care hospital. Int J Res Med Sci. 2015;3808-11.

21. Oman KS, Makic MBF, Fink R, Schraeder N, Hulett T, Keech T, et al. Nurse-directed interventions to reduce catheter-associated urinary tract infections. Am J Infect Control. 2012 Aug;40(6):548-53.

22. Wazait H d., Patel H r. h., Veer V, Kelsey M, Van Der Meulen J h. p., Miller R a., et al. Catheter-associated urinary tract infections: prevalence of uropathogens and pattern of antimicrobial resistance in a UK hospital (1996-2001). BJU Int. 2003 Jun 1;91(9):806-9.

23. Vyawahare CR, Gandham NR, Misra RN, Jadhav SV, Gupta NS, Angadi KM. Occurrence of catheterassociated urinary tract infection in critical care units. Med J Dr Patil Univ. 2015 Sep 1;8(5):585.

24. Sneka VS, Manonmoney SP. Incidence of Catheter Associated Urinary Tract Infection in Medical ICU in a Tertiary Care Hospital. Int J Curr Microbiol Appl Sci. 2017 Apr 15;6(4):662-9.

25. Sabir S, Ahmad Anjum A, Ijaz T, Asad Ali M, Ur Rehman Khan M, Nawaz M. Isolation and antibiotic susceptibility of E. coli from urinary tract infections in a tertiary care hospital. Pak J Med Sci. 2014 Mar;30(2):389-92.

26. Duszyńska W, Rosenthal VD, Szczęsny A, Woźnica E, Ulfik K, Ostrowska E, et al. Urinary tract infections in intensive care unit patients - a single-centre, 3-year observational study according to the INICC project. Anestezjol Intensywna Ter. 2016 Mar 11;48(1):1-6.

27. Kamat US, Fereirra A, Amonkar D, Motghare DD, Kulkarni MS. Epidemiology of hospital acquired urinary tract infections in a medical college hospital in Goa. Indian J Urol IJU J Urol Soc India. 2009;25(1):76-80.

28. Dalen DM, Zvonar RK, Jessamine PG. An evaluation of the management of asymptomatic catheter-associated bacteriuria and candiduria at The Ottawa Hospital. Can J Infect Dis Med Microbiol. 2005;16(3):166-70.

29. Kazi MM, Harshe A, Sale H, Mane D, Y M, e, et al. Catheter Associated Urinary Tract Infections (CAUTI) and Antibiotic Sensitivity Pattern from Confirmed Cases of CAUTI in a Tertiary Care Hospital: A Prospective Study. Clin Microbiol Open Access [Internet]. 2015 Apr 28 [cited 2017 Jul 31]; Available from: https://www.omicsonline.org/open-access/catheterassociated-urinary-tract-infections-cauti-and-antibioticsensitivitypattern-from-confirmed-cases-of-cauti-in-atertiary-care-hospital-aprospective-study-2327-50731000193.php?aid=50933

How to cite this article: Microbiological profile, comorbidity, incidence and rate analysis of catheter associated urinary tract infections in adult intensive care unit. Ramesh A, Janagond AB, Raja S, Gobinathan SP, Charles J. India. Indian J Microbiol Res 2018;5(1):38-43. 